\title{
Evaluation of Antimycobacterial and Synergistic Activity of Plants Selected Based on Cheminformatic Parameters
}

\author{
Nafise Rahgozar ${ }^{1,2}$, Gholamreza Bakhshi Khaniki ${ }^{1}$ and Soroush Sardari ${ }^{2 *}$ \\ ${ }^{1}$ Department of Agricultural Biotechnology Engineering, Payam-e-Noor University, Tehran 19395, Iran; \\ ${ }^{2}$ Drug Design and Bioinformatics Unit, Medical Biotechnology Department, Biotechnology \\ Research Center, Pasteur Institute of Iran, Tehran 13164, Iran
}

Received 3 July 2017; revised 22 August 2017; accepted 4 September 2017

\begin{abstract}
Background: Drug resistance is a major public health problem and a threat to progress made in bovine tuberculosis care and control worldwide. This study aimed at evaluating anti-mycobacterial and synergistic activity of some medicinal plants that were selected by cheminformatics studies against Mycobacterium bovis. Methods: Considering the strong synergistic antimycobacterial action of oleanolic acid in combination with tuberculosis drugs, NCBI database was explored to find the compounds with over $80 \%$ similarity to oleanolic acid, called S1. Plants containing S1-type compounds were traced to and resulted in five plants, including Datura stramonium, Boswellia serrata Lavandula stoechas, Rosmarinus officinalis, and Thymus vulgaris, as experimental samples. Crude extracts were prepared by percolation using $80 \%$ ethanol or as the product of a pharmaceutical company. The extracts were screened against Mycobacterium bovis using broth microdilution method and Alamar Blue Assay. Extracts from these plants were used in combination with isoniazid and ethambutol to investigate the possibility of synergy with respect to antimycobacterial activity. Results: The extracts from $D$. stramonium, $B$. serrata a, L. stoechas, R. officinalis, and T. Thymus vulgaris showed antimycobacterial activity of 375, 125, 250, $187.5,500 \mu \mathrm{g} / \mathrm{ml}$, respectively. The best synergistic results were for $L$. stoechas and $D$. stramonium in combination with ethambutol, the fractional inhibitory concentration index was $0.125 \mu \mathrm{g} / \mathrm{ml}$ for both. Conclusion: The observed antimycobacterial and synergistic activities are completely novel and obtained from targeted screening designed according to cheminformatics strategy. As for the synergistic action of the extracts, they could be used as supplements in bTB treatment. DOI: 10.29252/ibj.22.6.401
\end{abstract}

Keywords: Medicinal plants, Mycobacterium, Tuberculosis

Corresponding Author: Soroush Sardari

Drug Design and Bioinformatics Unit, Medical Biotechnology Department, Biotechnology Research Center, Pasteur Institute of Iran, Tehran 13164, Iran; Tel.: (+98-912) 2632484; Fax: (+98-21) 66480780; E-mail: ssardari@hotmail.com

\section{INTRODUCTION}

I $\mathrm{n}$ recent years, the number of people infected with bovine tuberculosis (bTB) has increased ${ }^{[1]}$. Mycobacterium bovis is the agent of bTB in a wide range of animal species and humansand results in a loss of three billion dollars annually worldwide. bTB is a disease that can infect cattle and human ${ }^{[2]}$ and is an old disease since the ancient times. Today, bTB is considered as an infectious disease in developing countries with a great cause of mortality among people $^{[2]}$. Currently, one third of the world population is infected with various forms of $\mathrm{TB}^{[3]}$, and each year 2-3 million people of the world die from TB infection or its complications ${ }^{[4]}$. Based on an estimate, nearly one billion people are affected by the disease between 2000 and $2020^{[5]}$.

HIV increases the risk of developing active TB, and this makes the treatment of TB difficult for the patients ${ }^{[6]}$. Unexpected drug resistance is one of the 
obstacles to the treatment of different kinds of TB. In some cases, the patients show resistance only to one of the antimycobacterial drugs. In some other cases, the contracted human or animal indicates resistance to two or more antimycobacterial drugs that can be the sign of existing multidrug-resistant species such as multidrugresistant bTB and extensively drug-resistant bTB $^{[7]}$. Unfortunately, the available antimycobacterial drugs are clearly limited and sometimes inefficient. Therefore, global efforts are required to control bTB among all sectors of society. According to recent surveys, plant products, as antimycobacterial agents, are the source of diverse and useful extracts and compounds ${ }^{[8]}$. Natural products are important sources of new antibiotics, and that is because of their amazing chemical variety. Also, natural products have been used and validated in traditional medicine during many centuries $^{[9]}$. Typically, the secondary metabolites of plants can be employed to fight for various environmentally originated infection ${ }^{[10]}$. Due to the large population of plants, targeted screening is important to save time and research cost. In addition to traditional medicine, cheminformatics can be used to find the possible extracts easier and faster. One of the methods to explore chemical space in natural products for the purpose of drug discovery is gathering the information about biologically active chemical compounds and correlated their structure and activities in relational datasets ${ }^{[11]}$.

A new approach in the current paper is to apply cheminformatics rational in order to select and consider traditionally used plants as a synergistic complementation for the conventional antimycobacterial drugs. The following plants are considered in this paper. Datura stramonium is a medicinal plant that has been used as analgesic and has been shown to have numerous alkaloids ${ }^{[12]}$. Lavender belongs to the family Lamiaceae and is a herbaceous, an aromatic and an evergreen plant ${ }^{[13]}$. Aerial parts of Lavandula stoechas have stronger antimicrobial effect than other parts of the plant ${ }^{[14]}$. It has been found that the leaves of this plant contain diterpene, large amounts of cyclic alcohols, flavonoids, and saponins. Among these, saponins have effective antibacterial properties ${ }^{[15]}$. Boswellia serrata is an aromatic resin plant that is obtained from several species of the genus Boswellia $^{[16]}$, a family of Burseraceae ${ }^{[17]}$. B. serrata generally contains $25-35 \%$ gum that is insoluble in alcohol and $60-70 \%$ of resin, and the rest includes some kinds of essential oils ${ }^{[18]}$. Boswellic acid is a series of pentacyclic triterpene and the main material in the resin of Boswellia ${ }^{[19]}$. Rosmarinus officinalis belongs to Lamiaceae family with green, sharp and fragrant leaves. Rosemary essential oil has antimicrobial and antioxidant properties that has been proven in several studies ${ }^{[20]}$. Thymus vulgaris is a member of Lamiaceae family that grows like a shrub with thin, reciprocal leaves and white flowers ${ }^{[21]}$. Thyme essential oil has antibacterial, antioxidant and antifungal properties ${ }^{[22]}$.

In this study, we aim to investigate the secondary metabolite chemical space of plants by using the cheminformatic methods and trace compounds existing in medicinal plants that have synergistic effects on antimycobacterial drugs and also to examine the extract of such plants for the mentioned activity.

\section{MATERIALS AND METHODS}

\section{Bioinformatics studies}

By performing a comprehensive literature search on natural compounds with synergistic properties on bTB drugs, oleanolic acid was found as an antimycobacterial plant compound with the synergistic effect, when combining with antimycobacterial $\operatorname{drugs}^{[23]}$. In National Center of Biotechnology Information (NCBI) database (https://pubchem.ncbi. nlm.nih.gov/), we searched compounds with more than $80 \%$ similarity to oleanolic acid. Then the plants containing similar compounds with oleanolic acid were searched. Finally, we found five plants as candidates for experimental examinations.

\section{Preparation of powder and extraction of plants}

Lavender, thyme, and rosemary plant extracts were prepared from Ebn-e-Masouyeh Pharmaceutical Company in Tehran, Iran. Boswellia and Datura plants, prepared from a herbal market in Tehran, were powdered with an electric mill. Percolation method was used to extract the plants. At first, $100 \mathrm{~g}$ of the powdered herb was transferred to the separatory funnel, and then $300 \mathrm{ml}$ of $80 \%$ ethanol was added. The mixture was remained at room temperature $\left(25{ }^{\circ} \mathrm{C}\right)$ for 24 hours, and gradual percolation was performed. This process was repeated three times at room temperature $\left(25{ }^{\circ} \mathrm{C}\right)$ in different days. The extracts were concentrated by using RV05 rotary evaporator from IKA Co. (Germany) at ambient temperature $^{[24]}$.

\section{Minimum inhibitory concentration determination of plant extracts and drugs}

(MIC)

MIC test was conducted for the plant extracts and for antimycobacterial drugs by using microdilution assay $^{[25]}$. Culture medium was the Middlebrook $7 \mathrm{H} 9$ broth from HiMedia, India. It was prepared according to the instructions on the container. In detail, $450 \mathrm{ml}$ of 
distilled water was added to $3.5 \mathrm{~g}$ of the powder, and 2 $\mathrm{mL}$ of glycerol was added ${ }^{[26]}$. Culture medium was sterilized by autoclave and then was refrigerated immediately after preparation. The culture medium requires addition of a supplement called Middlebrook OADC (oleaic acid, albumin, dextrose, and catalase), which was prepared separately, and at the time of testing was added to the culture medium. OADC was prepared using $0.85 \mathrm{~g}$ of sodium chloride, $0.06 \mathrm{ml}$ of oleic acid, $2 \mathrm{~g}$ of dextrose, $5 \mathrm{~g}$ albumin, $3 \mathrm{mg}$ catalase, and $100 \mathrm{ml}$ of distilled water.

The test compounds were prepared at the appropriate concentrations. Then, $1 \mathrm{mg}$ of the drug was dissolved in $1000 \mu \mathrm{l}$ of solvent (usually dimethyl sulfoxide), or $10 \mathrm{mg}$ of extract was dissolved in $1000 \mu \mathrm{l}$ of the solvent. At the beginning of the MIC test, $100 \mu \mathrm{l}$ of culture medium was added to each well of a 96-well plate. An amount of $80 \mu \mathrm{l}$ of culture medium was added to the first row of the plate, and then $20 \mu \mathrm{l}$ of each compound (extracts, ethambutol as a positive control, dimethyl sulfoxide as a negative control) were added to the first cell in each column. After performing the serial dilution, $100 \mu \mathrm{l}$ of BCG suspension (from BCG vaccine) equivalent to half McFarland were added to each cell, except the negative control column. The extract concentration tested was in the range of 500 to $1.95 \mu \mathrm{g} / \mathrm{ml}$. The plates were incubated at $37^{\circ} \mathrm{C}$ for four days ${ }^{[27]}$. After this time, Alamar blue solution was added to the culture medium. The plate was incubated at $37{ }^{\circ} \mathrm{C}$, and MIC test results were read after 48 and 72 hours $^{[28]}$. To read the MIC test result, the last cell that showed no color change was considered as $\mathrm{MIC}^{[29]}$.

\section{Investigation of the synergistic effect using MIC test}

To perform the test, half of the MIC of drugs was added to the culture medium. The rest of the test was done based on the previously explained steps. The fractional inhibitory concentration (FIC) was obtained using the following formulation and interpreted as synergy for $\mathrm{FIC} \leq 0.5$, no interaction for $\mathrm{FIC}=1$, and antagonism for $\mathrm{FIC} \geq 2^{[23]}$.

$$
\mathrm{FIC}=\mathrm{MIC}_{\text {in combination }} / \mathrm{MIC}_{\text {alone }}
$$

\section{RESULTS AND DISCUSSION}

By using cheminformatics knowledge, similar antimycobacterial compounds to the template active compound were found. The results of the search for similar compounds of oleanolic acid are listed in Table 1. The results of plants containing similar compounds of oleanolic acid are illustrated in Table 2. The MIC

Table 1. The results of search for similar compounds with oleanolic acid

\begin{tabular}{|c|c|c|c|}
\hline Compound name & Molecular formula & Molecular weight (g/mole) & Molecular structure \\
\hline Glycyrrhetinic acid & $\mathrm{C}_{30} \mathrm{H}_{48} \mathrm{O}_{3}$ & 470.68384 & \\
\hline Ursolic acid & $\mathrm{C}_{30} \mathrm{H}_{48} \mathrm{O}_{3}$ & 456.70032 & \\
\hline Boswellic acid & $\mathrm{C}_{30} \mathrm{H}_{48} \mathrm{O}_{3}$ & 456.70032 & \\
\hline Maslinic acid & $\mathrm{C}_{30} \mathrm{H}_{48} \mathrm{O}_{4}$ & 472.69972 & \\
\hline Asiatic acid & $\mathrm{C}_{30} \mathrm{H}_{48} \mathrm{O}_{5}$ & 488.69912 & \\
\hline Hederagenin & $\mathrm{C}_{30} \mathrm{H}_{48} \mathrm{O}_{4}$ & 472.69972 & \\
\hline
\end{tabular}




\begin{tabular}{|c|c|c|c|}
\hline Compound name & Molecular formula & Molecular weight (g/mole) & Molecular structure \\
\hline Echinocystic acid & $\mathrm{C}_{30} \mathrm{H}_{48} \mathrm{O}_{4}$ & 472.69972 & \\
\hline Maprounic acid & $\mathrm{C}_{30} \mathrm{H}_{48} \mathrm{O}_{3}$ & 456.70032 & \\
\hline Pomolic acid & $\mathrm{C}_{30} \mathrm{H}_{48} \mathrm{O}_{4}$ & 472.69972 & \\
\hline Rotundic acid & $\mathrm{C}_{30} \mathrm{H}_{48} \mathrm{O}_{5}$ & 488.69912 & \\
\hline Sumaresinolic acid & $\mathrm{C}_{30} \mathrm{H}_{48} \mathrm{O}_{4}$ & 472.69972 & \\
\hline Augustic acid & $\mathrm{C}_{30} \mathrm{H}_{48} \mathrm{O}_{4}$ & 472.69972 & \\
\hline Medicagenic acid & $\mathrm{C}_{30} \mathrm{H}_{46} \mathrm{O}_{6}$ & 502.68264 & \\
\hline Euscaphic acid & $\mathrm{C}_{30} \mathrm{H}_{48} \mathrm{O}_{5}$ & 488.69912 & \\
\hline Quillaic acid & $\mathrm{C}_{30} \mathrm{H}_{46} \mathrm{O}_{5}$ & 486.68324 & \\
\hline Daturaolone & $\mathrm{C}_{30} \mathrm{H}_{48} \mathrm{O}_{2}$ & 440.70092 & \\
\hline Sericic acid & $\mathrm{C}_{30} \mathrm{H}_{48} \mathrm{O}_{6}$ & 504.69852 & \\
\hline Wilforlide A & $\mathrm{C}_{30} \mathrm{H}_{46} \mathrm{O}_{3}$ & 454.68444 & \\
\hline Bassic acid & $\mathrm{C}_{30} \mathrm{H}_{46} \mathrm{O}_{5}$ & 486.68324 & \\
\hline Barbinervic acid & $\mathrm{C}_{30} \mathrm{H}_{48} \mathrm{O}_{5}$ & 488.69912 & \\
\hline
\end{tabular}


Table 2. Plants containing the similar compounds to oleanolic acid

\begin{tabular}{|c|c|}
\hline Chemical compound & Plant with similar compound \\
\hline Glycyrrhetinic acid & Glycyrrhiza glabra \\
\hline Ursolic acid & $\begin{array}{l}\text { Ocimum basilicum } \mathrm{L} . \\
\text { Mentha piperita } \\
\text { Origanum majorana } \\
\text { Prunus subg. Prunus } \\
\text { Lavandula } \\
\text { Rosmarinus officinalis } \\
\text { Thymus vulgaris }\end{array}$ \\
\hline $\begin{array}{l}\text { Boswellic acid } \\
\text { Maslinic acid } \\
\text { Asiatic acid } \\
\text { Hederagenin }\end{array}$ & $\begin{array}{l}\text { Boswellia } \\
\text { Olea europaea } \\
\text { Centella asiatica } \\
\text { Sapindus mukorossi }\end{array}$ \\
\hline Echinocystic acid & $\begin{array}{l}\text { Codonopsis lanceolata } \\
\text { Gleditsia sinensis Lam. } \\
\text { Eclipta prostrata }\end{array}$ \\
\hline Maprounic acid & Maprounea africana \\
\hline Pomolic acid & Cecropia pachystachya \\
\hline Rotundic acid & Ilex rotunda \\
\hline Sumaresinolic acid & Warszewiczia coccinea \\
\hline Augustic acid & Ambroma augusta \\
\hline Medicagenic acid & Medicago sativa \\
\hline Euscaphic acid & Rosa rugosa \\
\hline Quillaic acid & Saponaria officinalis \\
\hline Daturaolone & Datura stramonium \\
\hline Sericic acid & Vochysia divergens \\
\hline Wilforlide A & Tripterygium regelii \\
\hline Bassic acid & Eucalyptus camaldulensis \\
\hline Barbinervic acid & Clethra barbinervis \\
\hline
\end{tabular}

tests were conducted to determine the MIC of plant extract and drugs that Mycobacterium could not grow at that concentration. The MIC test result for isoniazid and ethambutol drugs were 0.62 and $0.31 \mu \mathrm{g} / \mathrm{ml}$, respectively. The synergistic effects of plant were determined by combining plant extracts with typical antimycobacterial drugs, isoniazid, and ethambutol. The results are indicated in Table 3 . As shown in the Table, MIC test results showed that B. serrata, D. stramonium, L. stoechas, $R$. officinalis, and T. vulgaris had antimycobacterial activity. Among these, $B$. serrata and T. vulgaris had the highest and the lowest antimycobacterial activity, respectively. The result of combining plant extracts with ethambutol demonstrated the MIC of $125 \mu \mathrm{g} / \mathrm{ml}$ for B. serrata alone and $62.5 \mu \mathrm{g} / \mathrm{ml}$ in combination with ethambutol, as well as the FIC value of $0.5 \mu \mathrm{g} / \mathrm{ml}$, which indicates the synergy activity. The MIC values of $L$. stoechas alone and in combination with ethambutol were 250 $\mu \mathrm{g} / \mathrm{ml}$ and $31.3 \mu \mathrm{g} / \mathrm{ml}$, respectively with a FIC value of 0.125 , suggesting a strong synergistic activity. The MICs of D. stramonium, T. vulgaris, and $R$. officinalis alone were 375,500 , and $187.5 \mu \mathrm{g} / \mathrm{ml}$ and in combination with ethambutol were 46.88, 250, and $31.3 \mu \mathrm{g} / \mathrm{ml}$, and their FICs were $0.125,0.5$, and 0.166 $\mu \mathrm{g} / \mathrm{ml}$, respectively, which shows the synergistic activities.

The MIC test result of combining plant extracts with isoniazid showed the MIC value of $125,250,500$ $\mu \mathrm{g} / \mathrm{ml}$ for B. serrata, L. stoechas, and T. vulgaris when used alone and of $31.3,62.5,125 \mu \mathrm{g} / \mathrm{ml}$ in combination, respectively. They all had a similar FIC equal to $0.25 \mu \mathrm{g} / \mathrm{ml}$ and showed a synergistic activity. However, the FICs of $D$. stramonium and $R$. officinalis were equal to $0.66 \mu \mathrm{g} / \mathrm{ml}$, which displays no interacting activity. Therefore, regarding the antimycobacterial and synergistic action of the mentioned plants, we can draw the conclusion that they could be used for supplementation along with regular

Table 3. The result of MIC test for plants and the determined synergistic effect

\begin{tabular}{lcccc}
\hline Plant/drug & $\begin{array}{c}\text { Individual MIC of } \\
\text { plant extract }(\boldsymbol{\mu g} / \mathbf{m l})\end{array}$ & $\begin{array}{c}\text { Combination MIC } \\
(\boldsymbol{\mu g} / \mathbf{m l})\end{array}$ & $\begin{array}{c}\text { Combined FIC } \\
\text { index }(\boldsymbol{\mu g} / \mathbf{m l})\end{array}$ & Synergy \\
\hline B. serrata/EMB & 125.0 & 62.50 & 0.500 & Sy \\
L. stoechas/EMB & 250.0 & 31.30 & 0.125 & Sy \\
D. stramonium/EMB & 375.0 & 46.88 & 0.125 & Sy \\
T. vulgaris/EMB & 500.0 & 250.00 & 0.500 & Sy \\
R. officinalis/EMB & 187.5 & 31.30 & 0.166 & Sy \\
B. serrata/INH & 125.0 & 31.30 & 0.250 & Sy \\
L. stoechas/INH & 250.0 & 62.50 & 0.250 & Sy \\
D. stramonium/INH & 375.0 & 250.00 & 0.660 & $\mathrm{~N}$ \\
T. vulgaris/INH & 500.0 & 125.00 & 0.250 & Sy \\
R. officinalis/INH & 187.5 & 125.00 & 0.660 & $\mathrm{~N}$ \\
\hline
\end{tabular}

EMB, ethambutol; INH, isoniazid; MIC, minimum inhibitory concentration; FIC, fractional inhibitory concentration; Sy, synergistic; $\mathrm{N}$, no interaction 
drugs in bTB treatment. The results of a study by a group of researchers in 2012 showed that Knowltonia vesicatoria, as a traditional plant in South Africa, has antimycobacterial activity. They also observed a synergistic activity when the plant extract is combined with isoniazid drug ${ }^{[30]}$. These results are consistent with ours that indicated the synergistic effect of the Boswellia and Lavandula in combination with isoniazid. A previous study has also exhibited that 8methoxypsoralen, a natural compound in many plant species, has antimycobacterial activity. This compound if combined with isoniazid, rifampin, and ethambutol drugs shows a synergistic effect against Mycobacterium $^{[31]}$. In our study, the plant extracts of Datura, Boswellia, and Lavandula genera showed synergistic effects in combination with ethambutol and isoniazid. Another study by Bapelaa et $a l^{[32]}$ has suggested that 7-methyljuglone and naphthoquinone isolated from Euclea natalensis roots show a synergistic effect when combining with isoniazid and rifampicin. They reported FIC indexes of 0.2 and 0.5 $\mu \mathrm{g} / \mathrm{ml}$, respectively. We, however, obtained FIC indexes of $0.5,0.125$, and 0.125 , respectively for Boswellia, Lavandula, and Datura in combination with ethambutol and $0.25 \mu \mathrm{g} / \mathrm{ml}$ for both Boswellia and Lavandula in combination with isoniazid. The novel antimycobacterial results and the advanced synergistic activity observed for the mentioned plants shows the efficacy of our applied new cheminformatics-based strategy in designing a targeted screening and enhancing the chance of drug discovery programs in finding hit and lead compounds.

\section{ACKNOWLEDGEMENTS}

Authors wish to thank the Ministry of Health and Medical Education, Iran, and Eastern Mediterranean Health Genomics and Biotechnology Network (EMGEN) for the financial support. Authors acknowledge Ebn-e-Masouyeh Pharmaceutical Company for providing lavender, thyme, and rosemary extracts.

CONFLICT OF INTEREST. None declared.

\section{REFERENCES}

1. Garnier T, Eiglmeier K, Camus JC, Medina N, Mansoor $\mathrm{H}$, Pryor M, Duthoy S, Grondin S, Lacroix C, Monsempe C, Simon S, Harris B, Atkin R, Doggett J, Mayes R, Keating L, Wheeler PR, Parkhill J, Barrell BG, Cole ST, Gordon SV, Hewinson RG. The complete genome sequence of Mycobacterium bovis. Proceedings of the national academy of sciences USA 2003; 100(13): 7877-7882.

2. Bryde L, Waheed U. Infectious diseases in developing countries. Scholars journal of applied medical sciences 2013; 1(4): 286-287.

3. Ghaffari-Fam S, Hosseini SR, Heydari H, VaseghiAmiri R, Daemi A, Sarbazi E, Nikbakht HA. Epidemiological patterns of Tuberculosis disease in the Babol, Iran. Journal of analytical research in clinical medicine 2015; 3(3): 164-169.

4. Newton SM, Lau C, Gurcha SS, Besra GS, Wright CW. The evaluation of forty-three plant species for in vitro antimycobacterial activities; isolation of active constituents from Psoralea corylifolia and Sanguinaria canadensis. Journal of ethnopharmacology 2002; 79(1): 57-67.

5. Zignol M, Gemert WV, Falzon D, Jaramillo E, Raviglione LBM. Modernizing surveillance of antituberculosis drug resistance: from special surveys to routine testing. Clinical infectious diseases 2011; 52(7): 901-906.

6. Center for Disease Control and Prevention (CDC). HIV and tuberculosis. Center for Disease Control and Prevention, 2013. Retrieved from: https://www.cdc.gov/ hiv/pdf/library/factsheets/hiv-tb.pdf

7. KNCV [Internet]. Tuberculosis MDR-TB and XDR-TB. October 2011. Retrieved from: https://www.kncvtbc. org/uploaded/2015/09/factsheet_tuberculosis_mdr-tb_ and_xdr-tb.pdf

8. Arya V. A review on anti-tubercular plants. International journal of pharmtech research 2011; 3(2): 872-880.

9. Dewick PM. Medicinal Natural Products, A Biosynthetic Approach. Edition 3, Nottingham: Wiley; 2009.

10. Guzman JD, Gupta A, Evangelopoulos D, Basavannacharya C, Pabon LC, Plazas EA, Muñoz DR, Delgado WA, Cuca LE, Ribon W, Gibbons S, Bhakta S. Anti-tubercular screening of natural products from Colombian plants: 3-methoxynordomesticine, an inhibitor of MurE ligase of Mycobacterium tuberculosis. Journal of antimicrobial chemotherapy 2010; 65(10): 2101-2107.

11. Wikipedia. Bioinformatics. 2016. Retrieved from: https://en.wikipedia.org/wiki/Bioinformatics.

12. Schulman ML, Bolton LA. Datura seed intoxification in two horses. Journal of the South African veterinary association 1998; 69(1): 27-29.

13. Umezu T, Nagano K, Kosakai K, Sakaniwa M, Morita M. Anticonflict effect of lavender oil and identification of its active constituents. Pharmacology biochemistry and behavior 2006; 85(4): 713-721.

14. Ozcan M. Antioxidant activities of rosemary, sage, and sumac extracts and their combinations on stability of natural peanut oil. Journal of medicinal food 2003; 6(3): 267-270.

15. Kim HM, Cho SH. Lavender oil inhibits immediatetype allergic reaction in mice and rats. Journal of pharmacy and pharmacology 1999; 51(2): 221-226.

16. Assimo Poulou AN, Zlatanos SN, Papageorgiou VP. 
Antioxidant activity of natural resins and bioactive triterpenes in oil substrate. Food chemistry 2005; 92(4): 721-727.

17. Kulkarni RR, Patki PS, Jog VP, Gandage SG, Patwardhan B. Treatment of osteoarthritis with a herbomineral formulation: a double-blind, placebocontrolled, crossover study. Journal of ethnopharmacology 1991; 33(1-2): 91-95.

18. Krohn K, Rao MS, Raman NV, Khalilullah M. Highperformance thin layer chromatographic analysis of anti-inflammatory triterpenoids from Boswellia serrata Roxb. Phytochemical analysis 2001; 12(6): 374-376.

19. Poeckel D, Werz O. Boswellic acids: biological actions and molecular targets. Current medicinal chemistry 2006; 13(28): 3359-3369.

20. Bakkali F, Averbeck A, Averbeck D, Idaomar M. Biological effects of essential oils-a review. Food and chemical toxicology 2008; 46(2): 446-475.

21. Vlog J, Studela J. Medicinal Plants. ed. 8. Iran: Ghoghnos; 1392.

22. James TK, Rahman A, Douglas JA. Control of Weeds in Five Herb Crops. New Zealand: Hamilton; 1991.

23. Ge F, Zeng F, Liu S, Guo N, Ye H, Song Y, Fan J, Wu $\mathrm{X}$, Wang $\mathrm{X}$, Deng $\mathrm{X}$, Jin $\mathrm{Q}$, Yu L. In vitro synergistic interactions of oleanolic acid in combination with isoniazid, rifampicin or ethambutol against Mycobacterium tuberculosis. Journal of medical microbiology 2010; 59(Pt 5): 567-572.

24. Balcha E, Mengiste B, Gebrelibanos M, Worku A, Ameni G. Evaluation of in-vitro anti-mycobacterial activity of selected medicinal plants in Mekelle, Ethiopia. World applied sciences journal 2014; 31(6): 1217-1220.

25. Wallace Er, Nash DR, Steele LC, Steingrube V. Susceptibility testing of slowly growing mycobacteria by a microdilution MIC method with $7 \mathrm{H} 9$ broth. Journal of clinical microbiology 1986; 24(6): 976-981.

26. BD. Middlebrook $7 \mathrm{H} 9$ broth with glycerol. Medical technologh, advancing the world of health, December 2006. Retrieved from: http://www.bd.com/europe/ regulatory/Assets/IFU/US/L007467\%2809\%29\%28120 6\%29.pdf

27. Banfi E, Scialino G, Monti-Bragadin C. Development of a microdilution method to evaluate Mycobacterium tuberculosis drug susceptibility. Journal of antimicrobial chemotherapy 2003; 52(5): 796-800.

28. Pagliotto AD, Caleffi-Ferracioli KR, Lopes MA, Baldin VP, Leite CQ, Pavan FR, Scodro RB, Siqueira VL, Cardoso RF. Anti-Mycobacterium tuberculosis activity of antituberculosis drugs and amoxicillin/clavulanate combination. Journal of microbiology, immunology and infection 2016; 49(6): 980-983.

29. Coban AY, Birinci A, Ekinci B, Durupinar B. Drug susceptibility testing of Mycobacterium tuberculosis by the broth microdilution method with $7 \mathrm{H} 9$ broth. Memórias do Instituto Oswaldo Cruz 2004; 99(1): 111113.

30. Labuschagné A, Hussein AA, Rodríguez B, Lall N. Synergistic Antimycobacterial actions of Knowltonia vesicatoria (L.f) sims. Evidence-based complementary and alternative medicine 2012; 2012: Article ID: 808979.

31. Fa G, Fanli Z, Na G, Junwen F, Yu S, Siguo L, Xiuping $\mathrm{W}$, Xuelin $\mathrm{W}$, Xuming $\mathrm{D}, \mathrm{Qi} \mathrm{J}, \mathrm{Lu} \mathrm{Y}$. In vitro synergistic activity between 8-methoxypsoralen and ethambutol, isoniazid, and rifampin when used in combination against Mycobacterium tuberculosis. World journal of microbiology and biotechnology 2010; 26(4): 623-628.

32. Bapelaa NB, Lall N, Fourie PB, Franzblau SG, Van Rensburg CE. Activity of 7-methyljuglone in combination with antituberculous drugs aginst Mycobacterium tuberculosis. Phytomedicine 2006; 13(9-10): 630-635. 